\title{
PREDIKSI KONSUMSI ENERGI PADA BANGUNAN MENGGUNAKAN METODE SUPPORT VECTOR MACHINE BERBASIS ALGORITMA GENETIKA
}

\author{
Wida Prima Mustika \\ Sekolah Tinggi Manajemen Informatika dan Komputer Nusa Mandiri \\ (STMIK Nusa Mandiri) \\ Jl. Kramat Raya No.18 Jakarta Pusat \\ wida.wpm@nusamandiri.ac.id
}

\begin{abstract}
Energy consumption is a demand for the amount of energy that must supply the building at any given time. Building energy consumption has continued increased over the last few decades all over the world, and Heating, Ventilating, and Air-Conditioning (HVAC), which has a catalytic role in regulating the temperature in the room, mostly accounted for of building energy use. Models created for in this study support vector machine and support vector machine-based models of genetic algorithm to obtain the value of accuracy or error rate or the smallest error value Root Mean Square Error (RMSE) in predicting energy consumption in buildings is more accurate. After testing the two models of support vector machines and support vector machines based on the genetic algorithm is the testing results obtained by using support vector machines where RMSE value obtained was 2,613. Next was the application of genetic algorithms to the optimization parameters $C$ and $\gamma$ values obtained RMSE error of 1.825 and a genetic algorithm for feature selection error RMSE values obtained for 1,767 of the 7 predictor variables and the selection attribute or feature resulting in the election of three attributes used. After that is done the optimization parameters and the importance of the value of feature selection mistake or error of the smallest RMSE of 1.537. Thus the support vector machine algorithm based on genetic algorithm can give a solution to the problems in the prediction of energy consumption rated the smallest mistake or error.
\end{abstract}

Keywords : Energy consumption, Genetic Algorithm, Support Machine, Fitur Selection, optimization parameters

\begin{abstract}
Abstrak
Konsumsi energi adalah permintaan yang digunakan untuk menunjukkan jumlah energi yang harus mensuplai bangunan pada waktu tertentu. Konsumsi energi bangunan telah terus meningkat selama beberapa dekade terakhir di seluruh dunia, dan penghangat, ventilasi dan pendingin udara atau biasa disebut dengan Heating, Ventilating, and Air-Conditioning (HVAC), yang memiliki peran katalisator dalam mengatur suhu dalam ruangan, diperhitungkan sebagian besar dari penggunaan
\end{abstract}


energi bangunan. Dalam penelitian ini dibuatkan model support vector machine dan model support vector machine berbasis algoritma genetika untuk mendapatkan nilai akurasi atau tingkat nilai kesalahan atau error terkecil Root Mean Square Error (RMSE) dalam memprediksi konsumsi energi pada bangunan lebih akurat. Setelah dilakukan pengujian dengan dua model yaitu support vector machines dan support vector machines berbasis algoritma genetika maka hasil yang didapat adalah pengujian dengan menggunakan support vector machines dimana didapat nilai RMSE adalah 2.613. Berikutnya dilakukan penerapan algoritma genetika untuk optimasi parameter $C$ dan $\gamma$ didapat nilai kesalahan RMSE sebesar 1.825 dan algoritma genetika untuk seleksi fitur didapat nilai kesalahan RMSE sebesar 1.767 dan dari 7 variabel prediktor dilakukan seleksi atribut atau fitur sehingga menghasilkan terpilihnya 3 atribut yang digunakan. Setelah itu dilakukan optimasi parameter dan seleksi fitur maka didapat nilai kesalahan atau error yang terkecil RMSE sebesar 1.537. Dengan demikian algoritma support vector machine berbasis algoritma genetika dapat memberikan solusi untuk permasalahan dalam prediksi konsumsi energi dengan nilai kesalahan atau error terkecil.

Kata kunci : Konsumsi energi, algoritma genetika, support vector machine, seleksi fitur, optimasi parameter

\section{PENDAHULUAN}

Konsumsi energi adalah permintaan yang digunakan untuk menunjukkan jumlah energi yang harus mensuplai bangunan pada waktu tertentu [1]. Konsumsi energi pada bagunan disebabkan karena meningkatnya kekhawatiran tentang pemborosan energi dan dampak negatif terhadap lingkungan [2]. Memprediksi konsumsi energi bangunan merupakan pendekatan yang penting dalam penghematan energi, yang menguntungkan baik individu dan masyarakat untuk lebih bijak merancang sebuah bangunan baru [3]. Prediksi konsumsi energi pada bangunan sangat penting untuk memperbaiki kinerja energi, dengan tujuan untuk mencapai penghematan energi dan mengurangi dampak lingkungan [4].

Penelitian terdahulu mengenai konsumsi energi pada bangunan seperti penelitian yang dilakukan oleh Yu, Haghighat, Fung, \& Yoshino yaitu menggunakan metode pohon keputusan (decision tree) untuk diterapkan pada bangunan perumahan di Jepang [5]. Penelitian yang dilakukan oleh Ekonomou, mengunakan Artificial Neural Network untuk prediksi jangka panjang konsumsi energi di Yunani [6]. Penelitian yang dilakukan oleh Li, Meng, Cai, Yoshino, \& Mochida yaitu Support Vector Machine untuk prediksi sebuah gedung perkantoran di Cina dengan beban pendinginan (cooling load) perjam pada musim panas [7].

Decision tree memiliki kelebihan melakukan klasifikasi dan prediksi pekerjaan dengan cepat tanpa melakukan upaya perhitungan yang banyak namun memiliki kelemahan bahwa metodeini lebih tepat untuk memprediksi variabel kategori dibandingkan untuk memprediksi variabel numerik [8]. Artificial Neural Network dengan Multilayer Perceptron Model (MLP) merupakan solusi kecil jaringan dengan kecepatan komputasi cepat yang memungkinan melatih set input data yang besar, 
otomatis generalisasi pengetahuan yang memungkinkan pengakuan terhadap set data dan meminimalisasi kesalahan di semua set data pelatihan [6]. Tetapi memiliki kelemahan banyak variabel yang harus dipertimbangkan ketika membangun MLP.

Support Vector Machine dapat memecahkan masalah dengan sampel yang kecil, non-linier dan masalah dimensi yang tinggi dengan menggunakan struktur minimalisasi resiko (structural risk minimization) bukan minimalisasi resiko empiris (empirical risk minimization) [9]. SVM digunakan untuk klasifikasi pola, dan ide dasarnya adalah: pemetaandata dalam ruang input dengan nonlinier mengubah keruang fitur dimensi tinggi, dimana masalah linear klasifikasi hyper-plane menjadi secara optimal [10]. Bila menggunakan SVM, dua masalah dihadapkan yaitu bagaimana memilih fitur yang optimal untuk SVM dan mengatur parameter terbaik. Kedua masalah sangat penting, karena pilihan fitur mempengaruhi kesesuaian parameter dan sebaliknya [11]. Fitur yang banyak atau sangat berhubungan, secara signifikan akan mengurangi tingkat akurasi klasifikasi, dengan menghapus beberapa fitur, tingkat akurasi efisiensi dan klasifikasi dapat diperoleh [12]. Selain pemilihan fitur, pengaturan parameter yang tepat dapat meningkatkan akurasi klasifikasi SVM [11]. Kunci parameter dalam SVM sangat penting, keakuratan klasifikasi atau regresi ditentukan oleh sekelompok parameter yang sesuai [9].

\section{METODOLOGI PENELITIAN}

Data mining adalah tentang memecahkan masalah dengan menganalisis data yang sudah ada dalam database. Data mining didefinisikan sebagai proses menemukan pola dalam data [13]. Data mining, sering juga disebut knowledge discovery in database (KDD), adalah kegiatan yang meliputi pengumpulan, pemakaian data historis untuk menemukan keteraturan, pola atau hubungan dalam set data berukuran besar [14].

Seleksi fitur digunakan untuk mengidentifikasi kuat prediksi subset dalam bidang database dan mengurangi jumlah field disajikan pada proses komputasi. Seleksi fitur mempengaruhi beberapa aspek klasifikasi pola, termasuk akurasi dari algoritma klasifikasi belajar, waktu yang diperlukan untuk belajar fungsi klasifikasi, contoh jumlah yang dibutuhkan untuk pembelajaran, dan biaya yang terkait dengan fitur. Dalam masalah aplikasi tertentu, tidak semuafitur ini sama pentingnya. Kinerja yang lebih baik dapat dicapai dengan membuang beberapa fitur. Dengan demikian, kita lakukan dengan menghilangkan noisy, yang tidak relevan dan berlebihan data, dengan tetap menjaga keutuhan membedakan dari data dengan caraseleksi fitur [15].

Genetic Algorithm (GA) atau Algoritma genetika mencoba untuk menirukan proses komputasi dengan seleksi alam yang beroperasi, dan menerapkannya untuk menyelesaikan masalah bisnis dan masalah penelitian [16].

\subsection{Desain Penelitian}

Menurut Berndtsson ada empat metode penelitian yang digunakan yaitu tindakan penelitian, studi kasus, eksperimen dan survey [17]. Dalam penelitian ini dilakukan beberapa langkah yang dilakukan dalam proses penelitian yaitu : 
1. Pengumpulan data

Pada bagian ini dijelaskan tentang bagaimana dan darimana data dalam penelitian ini didapatkan, ada dua tipe dalam pengumpulan data, yaitu pengumpulan data primer dan pengumpulan data sekunder. Pada tahap ini ditentukan data yang akan diproses. Mencari data yang tersedia, memperoleh data tambahan yang dibutuhkan, mengintegrasikan semua data dalam data set, termasuk variabel yang diperlukan dalam proses.

2. Pengolahan data awal

Pada bagian dijelaskan tentang tahap awal data mining. Pengolahan awal data meliputi proses input data ke format yang dibutuhkan, pengelompokan dan penentuan atribut data, serta pemecahan data (split) untuk digunakan dalam proses pembelajaran (training) dan pengujian (testing).

3. Metode yang diusulkan

Pada tahap ini data dianalisis, dikelompokan variabel mana yang berhubungan dengan satu sama lainnya. Setelah data dianalisis lalu diterapkan model-model yang sesuai dengan jenis data.

4. Eksperimen dan pengujian metode

Pada bagian ini dijelaskan tentang langkah-langkah eksperimen meliputi cara pemilihan arsitektur yang tepat dari model atau metode yang diusulkan sehingga didapatkan hasil yang dapat membuktikan bahwa metode yang digunakan adalah tepat.

5. Evaluasi dan validas

Pada tahap ini dilakukan evaluasi dan validasi hasil penerapan terhadap model penelitian yang dilakukan untuk mengetahui tingkat keakurasian model.

\subsection{Pengumpulan Data}

Dalam penelitian ini, data yang digunakan adalah data sekunder karena diperoleh dari data Energy efficiency dalam UCI machine learning repository [18]. Dimana data tersebut berisi 768 bangunan, dan memiliki 12 bentuk bangunan. dengan tanpa area kaca (glazing area)dan memiliki area kaca (glazing area).

Parameter bangunan yang digunakan termasuk dalam faktor perilaku energi bangunan berupa konstruksi bangunan dan analisis sifat termal bahan fisik yang digunakan yaitu kepadatan relatif (relative compactness), luas wilayah (surface area), area dinding (wall area), area atap (roof area), total tinggi bangunan (overall height), orientasi (orientation), area kaca (glazing area), dan beban pendinginan (cooling load).

Tabel 1. Energy Efficiency Data (UCI Repository)

\begin{tabular}{|c|c|c|c|c|c|c|c|c|}
\hline No. & $\begin{array}{c}\text { Relative } \\
\text { compactess }\end{array}$ & $\begin{array}{c}\text { Surface } \\
\text { arca }\end{array}$ & $\begin{array}{c}\text { Wall } \\
\text { area }\end{array}$ & $\begin{array}{c}\text { Roof } \\
\text { area }\end{array}$ & $\begin{array}{c}\text { Overall } \\
\text { teight }\end{array}$ & Orientation & $\begin{array}{c}\text { Glazing } \\
\text { area }\end{array}$ & $\begin{array}{c}\text { Cooling } \\
\text { load }\end{array}$ \\
\hline 1 & 0,98 & 514,50 & 294,00 & 110,25 & 7,00 & 2 & 0,00 & 21,33 \\
\hline 2 & 0,98 & 514,50 & 294,00 & 110,25 & 7,00 & 3 & 0,00 & 21,33 \\
\hline 3 & 0,98 & 514,50 & 294,00 & 110,25 & 7,00 & 4 & 0,00 & 21,33 \\
\hline 4 & 0,98 & 514,50 & 294,00 & 110,25 & 7,00 & 5 & 0,00 & 21,33 \\
\hline 5 & 0,98 & 514,50 & 294,00 & 110,25 & 7,00 & 2 & 0,10 & 26,47 \\
\hline 6 & 0,98 & 514,50 & 294,00 & 110,25 & 7,00 & 3 & 0,10 & 26,37 \\
\hline 7 & 0,98 & 514,50 & 294,00 & 110,25 & 7,00 & 4 & 0,10 & 26,44 \\
\hline 8 & 0,98 & 514,50 & 294,00 & 110,25 & 7,00 & 5 & 0,10 & 26,29 \\
\hline 9 & 0,98 & 514,50 & 294,00 & 110,25 & 7,00 & 2 & 0,10 & 25,95 \\
\hline 10 & 0.98 & 514.50 & 294.00 & 110.25 & 7.00 & 3 & 0.10 & 25.63 \\
\hline
\end{tabular}




\subsection{Pengolahan Data Awal}

Data pada setiap dataset yang tidak memiliki nilai akan dihapus dan tidak digunakan. Untuk mendapatkan data yang berkualitas, beberapa teknik yang dilakukan sebagai berikut [19]:

1. Data validation, kualitas input data dapat membuktikan tidak memuaskan karena ketidak lengkapan, kebisingan dan inkonsistensi. Dengan cara mengidentifikasi, memperbaiki dan menghapus data yang ganjil (outlier/noise), data yang tidak konsisten dan data yang tidak lengkap (Missing Value).

2. Data integration and transformation, untuk meningkatkan akurasi dan efisiensi algoritma. Data yang digunakan dalam penulisan ini bernilai numeric. Data ditransformasikan kedalam software Rapidminer.

3. Data size reduction and discritization, untuk memperoleh data set dengan jumlah atribut dan record yang lebih sedikit tetapi bersifat informative.

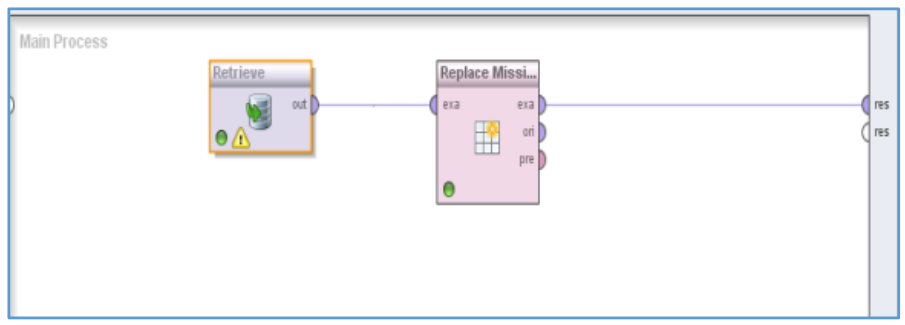

Gambar 1. Model Replace Missing

\subsection{Metode yang diusulkan}

Pada tahap modeling ini dilakukan pemprosesan data traning (90\%) dan data testing (10\%) sehingga akan membahas metode algoritma yang diuji dengan memasukan data konsumsi energi kemudian di analisa dan dikomparasi. Berikut ini bentuk gambaran metode algoritma yang akan diuji.

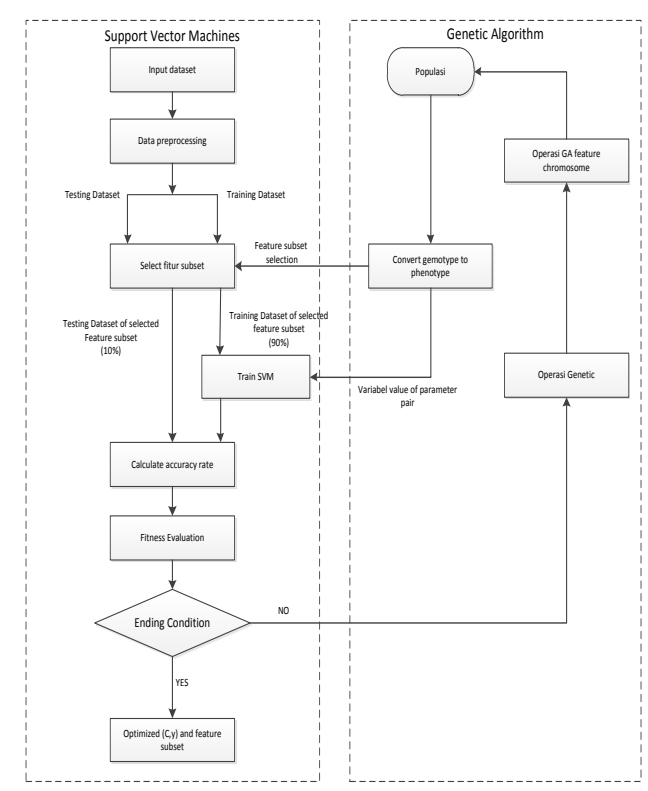

Gambar 2. Metode yang diusulkan 


\subsection{Eksperimen dan Pengujian Metode}

Pada penelitian ini dilakukan proses eksperimen dan pengujian model menggunakan dataset energy efficiency UCI Repository pada aplikasi RapidMiner 5. Dalam penelitian eksperimen digunakan spesifikasi software dan hardware sebagai alat bantu dalam penelitian ini pada Tabel 2

Tabel 2. Spesifikasi software dan hardware

\begin{tabular}{|c|c|}
\hline Software & Hardware \\
\hline $\begin{array}{c}\text { Sistem Operasi : } \\
\text { Microsoft Windows } 7\end{array}$ & : Intel Pentium Dual Core \\
\hline $\begin{array}{c}\text { Data Mining : Rapid } \\
\text { Miner Versi } 5\end{array}$ & Memory : 2 GB \\
\hline & Hardisk : $500 \mathrm{~GB}$ \\
\hline
\end{tabular}

\subsection{Evaluasi dan Validasi}

Hasil akhir dari penelitian ini adalah kegiatan valiadasi terhadap model yang digunakan, validasi ini dilakukan untuk menguji terhadap model prediksi yang dianggap paling optimal dengan prediksi kesalahan pada nilai Root Mean Square Error (RMSE).

\section{HASIL DAN PEMBAHASAN}

Hasil akhir dari penelitian ini adalah kegiatan valiadasi terhadap model yang digunakan, validasi ini dilakukan untuk menguji terhadap model prediksi yang dianggap paling optimal dengan prediksi kesalahan pada nilai Root Mean Square Error (RMSE)

\subsection{Hasil Eksperimen dan Pengujian Metode}

\subsubsection{Metode Support Vector Machine}

Berikut adalah gambar pengujian algoritma Support Vector Machine menggunakan metode $K$-Fold Cross Validation, data yang digunakan adalah data testing, dengan menggunakan software RapidMiner:

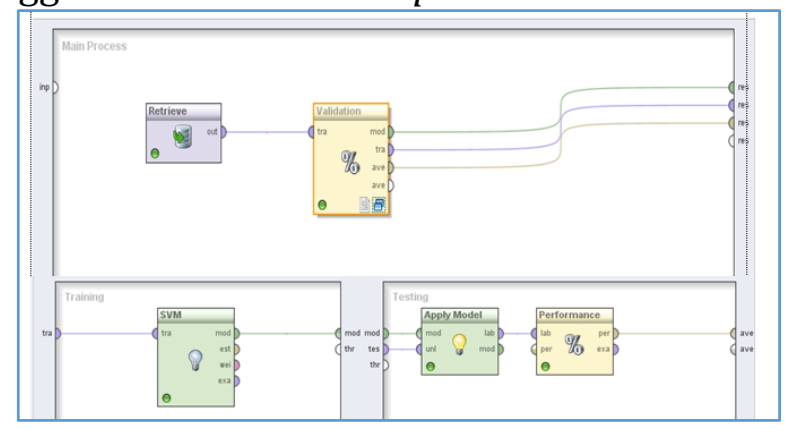

Gambar 3. Pengujian K-Fold Cross Validation algoritma Support Vector Machine

Setelah dilakukan pengujian dengan metode support vector machine didapat nilai Root Mean Square Error (RMSE) sebesar 2.613. 


\subsubsection{Parameter Support Vector Machines berbasis Genetic Algorithm}

Berikut gambar pengujian algoritma Support Vector Machine berbasis Genetic Algorithm untuk optimasi parameter menggunakan K-Fold Cross Vlidation dengan menggunakan Rapid Miner :

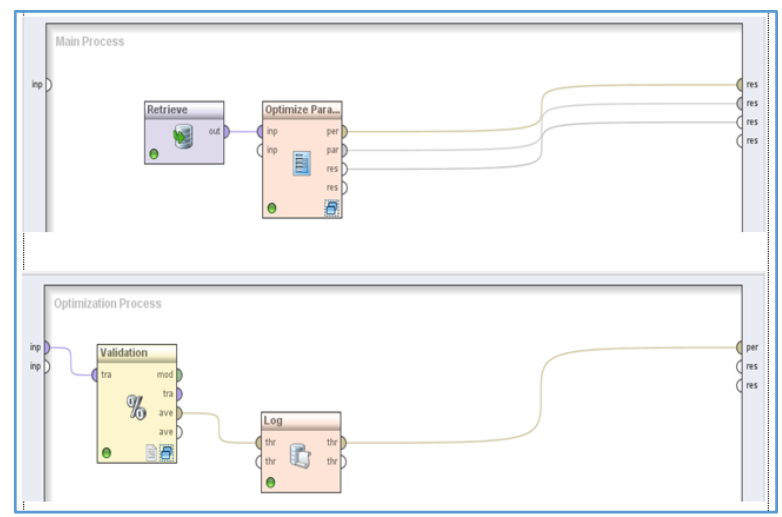

Gambar 4. Pengujian Optimasi Parameter Support Vector Machine berbasis Genetic Algorithm

Untuk meningkatkan kinerja prediksi maka dilakukan uji coba untuk pemilihan parameter dengan menggunakan Genetic Algorithm yaitu paramater C dan $\gamma$. Setelah dilakukan pengujian maka didapatkan nilai Root Mean Square Error (RMSE) sebesar 1.825 .

\subsubsection{Seleksi Fitur Support Vector Machines berbasis Genetic Algorithm}

Berikut gambar pengujian algoritma Support Vector Machine berbasis Genetic Algorithm untuk seleksi fitur menggunakan K-Fold Cross Vaidation dengan menggunakan Rapid Miner :

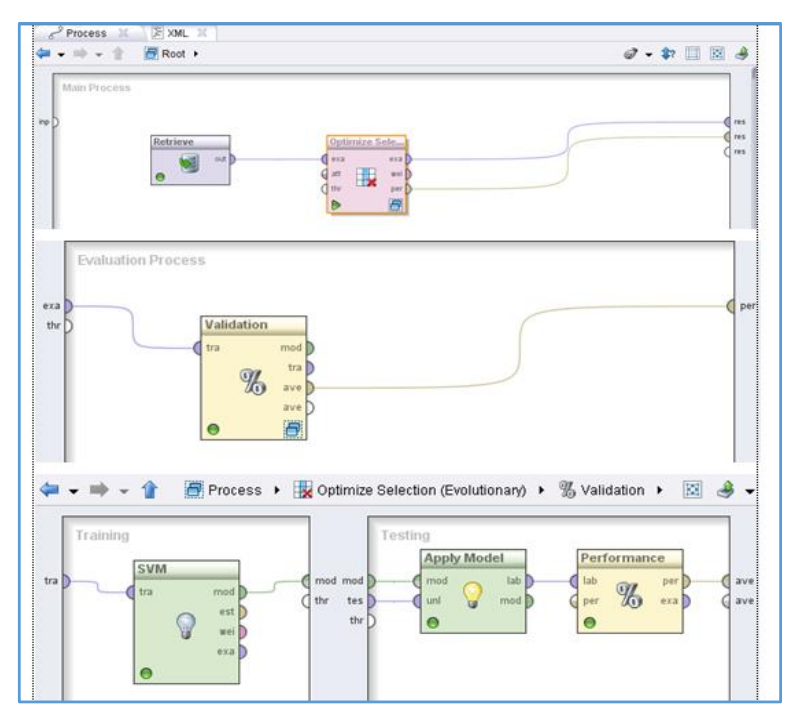

Gambar 5. Pengujian Feature Selection Support Vector Machine berbasis Genetic Algorithm 
Dalam penelitan ini penulis melakukan seleksi fitur atau atribut yang digunakan yaitu kepadatan relatif (relative compactness), luas wilayah (surface area), area dinding (wall area), area atap (roof area), total tinggi bangunan (overall height), orientasi (orientation), area kaca (glazing area), dan satu atribut sebagai label yaitu beban pendinginan (cooling load).

\begin{tabular}{|c|c|c|c|c|c|}
\hline Role & Name & Type & Statistics & Range & Missings \\
\hline label & coolingload & real & avg $=24.296+1.9 .648$ & {$[11.270 ; 46.230]$} & 0 \\
\hline regular & relativecompacthess & real & $\operatorname{avg}=0.763+1.0 .103$ & {$[0.620 ; 0.980]$} & 0 \\
\hline regular & suffacearea & numeric & $\arg =672.280+1.86 .520$ & {$[514.500 ; 808.500]$} & 0 \\
\hline regular & wallarea & numeric & avg $=317.275+1.41 .842$ & {$[245.000 ; 416.500]$} & 0 \\
\hline regular & roofarea & numeric & $\arg =177.502+1.44 .442$ & {$[110.250 ; 220.500]$} & 0 \\
\hline reggular & overallheight & numeric & $\arg =5.250+1-1.759$ & {$[3.500 ; 7.000]$} & 0 \\
\hline regulari & orientation & integer & axg $=3.430+1-1.047$ & {$[2.000 ; 5.000]$} & 0 \\
\hline regular & glazingarea & numeric & $a v g=0.226+1.0 .138$ & {$[0.000 ; 0.400]$} & 0 \\
\hline
\end{tabular}

Gambar 6. Feature Selection sebelum dilakukan pengujian

Dari 7 variabel prediktor dilakukan seleksi atribut atau fitur sehingga menghasilkan terpilihnya 3 atribut yang digunakan, yaitu ; wall area, overall height dan glazing area yang mempengaruhi beban pendinginan (cooling load) dengan nilai $R M S E$ yaitu 1.767 .Sedangkan atribut atau fitur lainnya seperti: relative compactness, surface area, roof area, dan orientation tidak berpengaruh terhadap bobot atribut.

\begin{tabular}{|c|c|c|c|c|c|}
\hline Role & Nâl & Type & Statistics & Range & Minsings \\
\hline |abel & coolingload & real & $a x y=24.508+1.95 .513$ & {$[10.900 ; 480.030]$} & 0 \\
\hline regulariar & wallarea & numeric & $a y=318.500+1.43 .626$ & {$[245.000 ; 416.500]$} & 0 \\
\hline regullari & overallheight & numeric & $a y=5.250+1 \cdot 1.751$ & {$[3,500 ; 7,0000]$} & 0 \\
\hline regulatar & glazingarea & numeric & $a y=0.234+1 \cdot 0.133$ & (0.000;:0.400] & 0 \\
\hline
\end{tabular}

Gambar 7. Feature Selection sesudah dilakukan pengujian

\subsubsection{Seleksi Fitur dan Parameter Support Vector Machines berbasis Genetic Algorithm}

Setelah dilakukan seleksi fitur dan parameter, untuk mendapatkan nilai RMSE yang optimal langkah berikutnya dilakukan pengujian terhadap penerapan genetika algoritma untuk seleksi fitur dan parameter. Berikut gambar pengujian algoritma Support Vector Machine berbasis Genetic Algorithm untuk seleksi fitur dan parameter menggunakan dengan menggunakan Rapid Miner: 


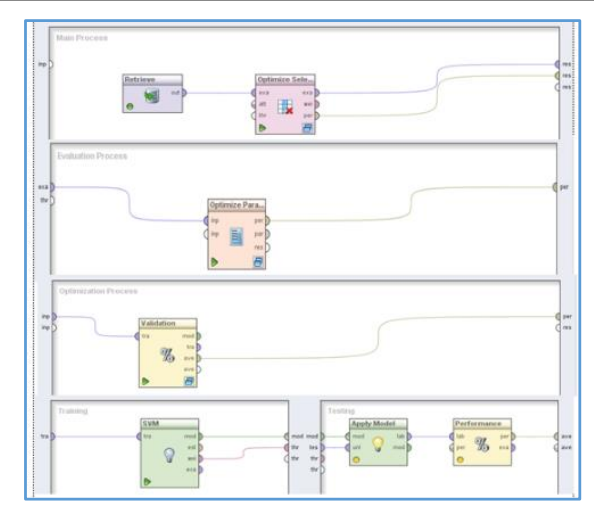

Gambar 8. Pengujian Feature Selection dan Parameter Support Vector Machine berbasis Genetic Algorithm

Setelah dilakukan pengujian maka didapatkan nilai Root Mean Square Error (RMSE) sebesar 1.537.

\subsection{Pembahasan}

\subsubsection{Evaluasi dan Validasi Hasil}

Pengaruh faktor-faktor beban pendinginan (cooling load) sangat signifikan untuk memprediksi konsumsi energi pada bangunan. Berdasarkan hasil pengujian yang dilakukan untuk memecahkan masalah prediksi hasil prediksi konsumsi energi, dapat disimpulkan bahwa eksperiment menggunakan metode support vector machine mempunyai nilai RMSE sebesar 2.613.

Berikutnya dilakukan penerapan algoritma genetika untuk optimasi parameter $C$ dan $\gamma$ didapat nilai kesalahan $R M S E$ sebesar 1.825 dan algoritma genetika untuk seleksi fitur didapat nilai kesalahan RMSE sebesar 1.767 dan dari 7 variabel prediktor yaitu kepadatan relatif (relative compactness), luas wilayah (surface area), area dinding (wall area), area atap (roof area), total tinggi bangunan (overall height), orientasi (orientation), area kaca (glazing area), dan beban pendinginan (cooling load), dilakukan seleksi atribut atau fitur sehingga menghasilkan terpilihnya 3 atribut yang digunakan yaitu ; wall area, overall height dan glazing area yang mempengaruhi beban pendinginan (cooling load). Setelah itu dilakukan optimasi parameter dan seleksi fitur didapat nilai error kesalahan yang paling kecil dengan nilai RMSE sebesar 1.537.

\subsubsection{Implikasi Penelitian}

Hasil dari penelitian ini mempunyai implikasi terhadap prediksi konsumsi energi pada bangunan yaitu meliputi implikasi terhadap aspek

1. Implikasi terhadap aspek sistem

Hasil evaluasi menunjukkan penerapan Algoritma Genetika (Genetic Algorithm) untuk seleksi fitur dan optimasi parameter pada Support Vector Machines (SVM) mampu menunjukkan aspek berupa atribut yang berpengaruh terhadap hasil dari prediksi konsumsi energi dan mendapat nilai error yang paling kecil. Dari hasil ini menunjukkan bahwa metode Support 
Vector Machine berbasis Algoritma Genetika merupakan metode yang cukup baik dalam klasifikasi data. Dengan demikian penerapan Algoritma Genetika pada Support Vector Machine dapat memberikan pemecahan masalah untuk memprediksi konsumsi energi pada bangunan dan dapat membantu dalam pengambilan keputusan dalam merancang bangunan baru dengan hemat energi bagi arsitek bangunan dan di Indonesia dapat diterapkan oleh Kementrian Pekerjaan Umum.

2. Implikasi terhadap aspek manajerial

Dari hasil penelitian ini diketahui bahwa penerapan Algoritma Genetika pada Support Vector Machine dapat membantu dalam pengambilan keputusan untuk merancang bangunan baru bagi arsitek bangunan menggunakan software RapidMiner, untuk itu diperlukan peningkatan kemampuan manajerial dari arsitek bangunan agar mampu membuat perancangan bangunan baru dengan perencanaan yang baik.

3. Implikasi terhadap aspek penelitian lanjutan

Dalam penelitian ini menggunakan penerapan algoritma genetika pada Support Vector Machine untuk mengetahui kehandalan metode, maka pana penelitian selanjutnya dapat dilakukan pengunaan data set lebih dari satu. Penelitian semacam ini dapat dikembangkan pada unit bisnis serupa atau yang lain. Pengembangan dapat dilakukan dengan menggunakan metode Neural Network, Decision Tree, C4.5 dan sebagainya.

\section{SIMPULAN}

Pengujian dengan mengunakan support vector machine berbasis Genetic Algorithm untuk seleksi atribut dengan penyesuaian pada parameter C dan $\gamma$. Dari 7 variabel prediktor dilakukan seleksi atribut sehingga menghasikan terpilihnya 3 atribut yang digunakan. Maka dapat disimpulkan pengujian data energy efficiency UCI data set, hasil eksperimen support vector machine sebelum dan sesudah dilakukan seleksi atribut dan optimasi parameter dengan algoritma genetika, menunjukkan bahwa ada perbedaan yang signifikan pada pada nilai rata-rata RMSE. Sehingga dapat disimpulkan bahwa penerapan model SVM dengan Algoritma Genetika untuk seleksi fitur dan optimasi parameter terbukti meningkatkan akurasi dalam prediksi konsumsi energi pada bangunan dengan nilai error kesalahan terkecil

\section{DAFTAR PUSTAKA}

[1] Wu, L., Kaiser, G., Solomon, D., Winter, R., Boulanger, A., \& Anderson, R. (2011). Improving Efficiency and Reliability of Building Systems Using Machine Learning and Automated Online Evaluation.

[2] Tsanas, A., \& Xifara, A. (2012). Accurate quantitative estimation of energy performance of residential buildin using statistical machine learning tools. Energy and Buildings, 560-567. 
[3] Xiang, Hai Zhao, frederic M. (2009). Parallel Support Vector Machines Applied to the Prediction of Multiple Buildings Energy Consumption, 4(2), 1-17.

[4] Zhao, H., \& Magoulès, F. (2012). A review on the prediction of building energy consumption. Renewable and Sustainable Energy Reviews, 16(6), 35863592.

[5] Yu, Z., Haghighat, F., Fung, B. C. M., \& Yoshino, H. (2010). A decision tree method for building energy demand modeling. Energy and Buildings, 42(10), 1637-1646.

[6] Ekonomou, L. (2010). Greek long-term energy consumption prediction using artificial neural networks. Energy, 35(2), 512-517. ScienceDirect.

[7] Li, Q., Meng, Q., Cai, J., Yoshino, H., \& Mochida, A. (2009). Applying support vector machine to predict hourly cooling load in the building. Applied Energy, 86(10).

[8] Yu, Z., Haghighat, F., Fung, B. C. M., \& Yoshino, H. (2010). A decision tree method for building energy demand modeling. Energy and Buildings, 42(10), 1637-1646.

[9] Yuxia, H., \& Hongtao, Z. (2012). Chaos Optimization Method of SVM Parameters Selection for Chaotic Time Series Forecasting. Physics Procedia, $25,588-594$.

[10] Wang, S., \& Meng, B. (2011). Parameter Selection Algorithm for Support Vector Machine. Procedia Environmental Sciences, 11, 538-544.

[11] Huang, C.-L., \& Wang, C.-J. (2006). A GA-based feature selection and parameters optimizationfor support vector machines. Expert Systems with Applications, 31(2).

[12] Lin, S.-W., Chen, S.-C., Wu, W.-J., \& Chen, C.-H. (2009). Parameter determination and feature selection for back-propagation network by particle swarm optimization. Knowledge and Information Systems, 21(2), 249-266.

[13] Witten, I. H., Frank, E., \& Hall, M. A. (2011). Data Mining Practical Machine Learning Tools And Techniques. Burlington, Usa: Morgan Kaufmann Publishers.

[14] Santosa, Budi (2007). Data Mining: Teknik Pemanfaatan Data Untuk Keperluan Bisnis. Yogyakarta: Graha Ilmu 
[15] Zhao, H. (2011). New Parallel Support Vector Regression for Predicting Building Energy Consumption. IEEE Symposium Series on Computational Intelligence. Paris : Chatenay Malabry.

[16] Larose, D. T. (2007). Data Mining Methods And Models. New Jersey: A John Wiley \& Sons.

[17] Berndtsson, Hansson, Olsson, \& Lundell. (2008). Thesis Projects. A Guide For Students In Computer Science and Information Systems. London: Springer.

[18] UCI (2012). Energy Efficiency. November 30. http://archive.ics.uci.edu/ml/machinelearningdatabase/00242/ENB2012_data.xlsx

[19] Vercellis, C. (2009). Business Intelligence Data Mining And Optimization For Decision Making. United Kingdom: A John Wiley And Sons, Ltd.,Publication. 